\title{
Evaluation and management of extrahepatic manifestations of nonalcoholic fatty liver disease
}

\author{
Karn Wijarnpreecha', Elizabeth S. Aby ${ }^{2}$, Aijaz Ahmed ${ }^{3}$, and Donghee Kim ${ }^{3}$ \\ 'Division of Gastroenterology and Hepatology, Mayo Clinic College of Medicine, Jacksonville, FL; '²ivision of Gastroenterology and \\ Hepatology, Department of Medicine, University of Minnesota, Minneapolis, MN; ${ }^{3}$ Division of Gastroenterology and Hepatology, Stan- \\ ford University School of Medicine, Stanford, CA, USA
}

\begin{abstract}
Nonalcoholic fatty liver disease (NAFLD) is a multisystemic disease and a rapidly growing cause of chronic liver disease in children and adults worldwide. Diagnosis and management of extrahepatic manifestations of NAFLD, including cardiovascular disease (CVD), type 2 diabetes mellitus, metabolic syndrome, chronic kidney disease, obstructive sleep apnea, polycystic ovarian syndrome, hypothyroidism, psoriasis, and extrahepatic malignancy are crucial for the treatment of patients with NAFLD. The leading cause of death in NAFLD is primarily from CVD, followed by liver-related mortality, extrahepatic cancer, liver cancer, and diabetes-related mortality. Therefore, clinicians need to identify high-risk patients earlier in the disease course and be aware of the extrahepatic manifestations of NAFLD to improve liver disease outcomes. In this review, we focus on the monitoring and management of the extrahepatic manifestations of NAFLD. (Clin Mol Hepatol 2021;27:221-235)
\end{abstract}

Keywords: Fatty liver; Therapeutics; Cardiovascular diseases; Non-alcoholic fatty liver disease; Liver cirrhosis

\section{INTRODUCTION}

Nonalcoholic fatty liver disease (NAFLD) represents a spectrum of liver disease characterized by triglyceride deposits in hepatocytes without secondary causes of liver disease, including significant alcohol consumption. ${ }^{1}$ NAFLD represents a broad clinical spectrum of diseases ranging from simple hepatic steatosis through steatosis with inflammation and hepatocyte degeneration (nonalcoholic steatohepatitis [NASH]) that can lead to advanced fibrosis, cirrhosis, and hepatocellular carcinoma. ${ }^{1}$ NAFLD is a sig- nificant health problem worldwide, and its burden is expected to rise. A meta-analysis demonstrated that the prevalence of NAFLD is $25.2 \%$ worldwide, with the highest in South America and the Middle East (30.5\% and 31.8\%, respectively) and lowest in Africa $(13.5 \%){ }^{2}$ Despite the high prevalence of NAFLD in the general population, only a minority of patients with NAFLD will progress to NASH with advanced fibrosis or develop liver-related complications. $^{3}$

Recently, an international consensus group suggested considering a new acronym, metabolic (dysfunction) associated fatty liver

\begin{abstract}
Abbreviations:
AASLD, American Association for the Study of the Liver Disease; Cl, confidence interval; CKD, chronic kidney disease; CVD, cardiovascular disease; DPP-4, dipeptidyl peptidase 4; EASL, European Association for the Study of the Liver; GLP-1, glucagon-like peptide 1; HR, hazard ratio; IRR, incidence rate ratio; LDL, low-density lipoprotein; MAFLD, metabolic associated fatty liver disease; NAFLD nonalcoholic fatty liver disease; NASH, nonalcoholic steatohepatitis; OR, odds ratio; OSA, obstructive sleep apnea; PCOS, polycystic ovarian syndrome; PIVENS, Pioglitazone versus Vitamin E versus Placebo for the Treatment of Nondiabetic Patients with NASH; RAS, renin-angiotensin system; SGLT-2, sodium-glucose cotransporter type-2; TNF, tumor necrosis factor; UDCA, ursodeoxycholic acid
\end{abstract}

Corresponding author : Donghee Kim

Division of Gastroenterology and Hepatology, Stanford University School of Medicine, 300 Pasteur Drive, Stanford, CA 94304, USA

Tel: +1-650-497-9261, Fax: +1-650-723-5488

E-mail: messmd@chol.com,dhkimmd@stanford.edu

https://orcid.org/0000-0003-1919-6800 
disease (MAFLD), to more accurately reflect the current knowledge of the disease pathophysiology and help with risk stratification and management due to the heterogeneity of clinical presentation of fatty liver disease. ${ }^{4}$ Even though MAFLD may more appropriately reflect the relevant risk factors for the disease better than NAFLD, the term remains vague. Prior to a name change, an improved understanding of the pathogenesis, natural history, and treatment of NAFLD is needed. ${ }^{5}$ NAFLD is a multisystem disease with effects, ${ }^{6}$ thus physicians should be aware of the manifestations of NAFLD beyond the liver, such as cardiovascular disease $(C V D)$, with the goal of early recognition and management. ${ }^{7,8}$

Previous studies have shown that the most common cause of death associated with NAFLD is CVD, independent of other metabolic comorbidities, followed by extrahepatic cancer and liver-related complications. ${ }^{1,9,10} \mathrm{~A}$ recent USA study reported that the cause of death in NAFLD was more likely to be CVD (about 20\%), whereas mortalities for extrahepatic cancer and diabetes compared with CVD showed a more pronounced increase annually during the recent decade." In this review, we focus on recognizing and managing the extrahepatic manifestations of NAFLD.

\section{CVD}

CVD is the major cause of death among individuals with NAFLD. ${ }^{12}$ Risk factors for NAFLD are similar to those for CVD, including insulin resistance, type 2 diabetes, male sex, hypertension, dyslipidemia, metabolic syndrome, and obesity. ${ }^{12,13}$ NAFLD is associated with an increased risk of incident CVD independent of traditional risk factors and components of metabolic syndrome. ${ }^{12}$ A recent meta-analysis showed that NAFLD is associated with a higher risk of fatal and non-fatal cardiovascular events, such as stroke, angina, myocardial infarction, or coronary revascularization, compared to those without NAFLD. ${ }^{14}$ It should be noted that patients with NAFLD who are not overweight also have an increased risk of CVD compared with those without NAFLD who are not overweight. ${ }^{15}$ In addition, the risk of CVD in non-overweight NAFLD (hazard ratio [HR], 10.4; 95\% confidence interval [CI], 2.61-44.0) was higher than those who are overweight in the setting of NAFLD (HR, 3.14; 95\% Cl, 0.84-13.2). ${ }^{15}$ Further studies are needed to confirm this finding.

The pathophysiologic mechanisms that link NAFLD and CVD, including pro-inflammatory mediators, altered coagulation and fibrinolysis, shared metabolic CVD risk factors, have been summarized in the previous literature. ${ }^{7,16}$ Moreover, evidence suggests that NAFLD is associated with an increased risk of premature atherosclerosis. ${ }^{12,17,18}$ Thus, aggressive screening for metabolic and CVD risk factors as well as risk factor modification are essential strategies to reduce the risk of CVD mortality. ${ }^{19}$

The European Association for the Study of the Liver (EASL) and American Association for the Study of the Liver Disease (AASLD) guidelines recommend screening for metabolic risk factors in patients with NAFLD; however, at this time there is no role for screening asymptomatic individuals with NAFLD for CVD. ${ }^{1,20}$ An algorithm to screen and manage metabolic risk factors, including obesity, diabetes, dyslipidemia, and hypertension, in patients with NAFLD, has been proposed by Wong and Lim. ${ }^{19}$ Currently, there are nonpharmacological, pharmacological, and surgical management strategies with the potential to reduce CVD risk in individuals with NAFLD.

\section{Nonpharmacological strategy}

Nonpharmacological management or lifestyle modifications, including weight loss, increased physical activity, and diet control, should be recommended to every patient with NAFLD. Lifestyle modifications, especially in the early stages, are associated with reduced CVD risk as well as improved results of blood tests for liver function, hepatic steatosis, liver histology, and fibrosis in patients with NAFLD.' Greater than 5\% weight loss is associated with an improvement in hepatic steatosis and reduction in NAFLD activity score. In contrast, weight loss of greater than $10 \%$ is also associated with fibrosis regression. ${ }^{1,20,21}$ Despite the benefits of weight loss, few can achieve significant weight loss with lifestyle interventions. Only $50 \%$ of patients in an intensive lifestyle intervention program were able to achieve greater than $7 \%$ weight loss at 12-month follow-up, and there were concerns regarding the sustainability of the weight loss. ${ }^{21}$

A calorie-restricted diet for more than 1 year has been shown to significantly lower atherosclerosis risk in NAFLD. ${ }^{22,23}$ In addition, caloric restriction has been shown to reduce liver fat content. ${ }^{24}$ Daily reduction by 500-1,000 kcal has been recommended for patients with NAFLD by several guidelines. ${ }^{1,20,25}$ Moreover, several studies recommend restricting processed food, red meat, saturated fat, as well as beverages containing high fructose and artificial sweeteners. ${ }^{1,20,26-28}$ An epidemiological study comprised of an ethnically diverse population showed that decreasing consumption of red and processed meat, cholesterol, and poultry and increasing fiber consumption may reduce the risk of NAFLD and NAFLD-related cirrhosis. ${ }^{29}$ Recently, one study showed that a low 
carbohydrate Mediterranean diet decreases liver fat more than a low-fat diet in NAFLD. ${ }^{30} \mathrm{~A}$ large randomized controlled trial demonstrated a decreased incidence of CVD events in individuals consuming a Mediterranean diet based on extra-virgin olive oil and nuts compared to consuming a reduced-fat diet. ${ }^{31} \mathrm{~A}$ recent systematic review and meta-analysis showed that in patients with NAFLD, adherence to the Mediterranean diet reduced serum triglyceride, total cholesterol, body weight, and insulin resistance, all of which are closely tied to cardiovascular health. ${ }^{32}$ EASL and AASLD guidelines both agree that patients with NAFLD should avoid substantial amounts of alcohol consumption, ${ }^{1,20}$ less than $30 \mathrm{~g} /$ day in men and $20 \mathrm{~g} /$ day in women. ${ }^{20}$ Alcohol abstinence is highly suggested for those with NASH-cirrhosis to reduce the risk of hepatocellular carcinoma. ${ }^{20}$ Interestingly, coffee consumption can be considered as a potential lifestyle modification based on the EASL guidelines; this modification is suggested given a recent systematic review that demonstrated that coffee consumption is inversely related to the severity of steatohepatitis. ${ }^{20,33}$ Further work has shown that more than 3 cups of coffee per day is associated with a lower risk of CVD and risk of death post-myocardial infarction. ${ }^{20,34-36}$

Inadequate physical activity or sedentary lifestyle is a risk factor associated with NAFLD and CVD. ${ }^{37-39}$ A recent US populationbased study showed that the prevalence of meeting the physical activity guidelines ( $\geq 150 \mathrm{~min} /$ week) was markedly higher in subjects without NAFLD than those with NAFLD, which was mostly attributable to the higher prevalence of leisure-time physical activity in those without NAFLD. ${ }^{37}$ Physical activity is a proven therapeutic strategy to improve liver fat content, insulin resistance, and decrease the risk of CVD. ${ }^{40-42}$ In a systemic review and meta-analysis, exercise interventions were shown to be associated with a reduction in liver fat in spite of minimal to no weight loss. ${ }^{43}$ In a recent longitudinal USA population-based study, increasing total physical activity was associated with a lower overall and cardiovascular mortality in individuals with NAFLD. ${ }^{44}$ In patients with NAFLD, the EASL guideline recommends moderate-intensity aerobic physical activity in 3-5 sessions for a total of 150-200 minutes per week. ${ }^{20}$ Although various types of physical activity have demonstrated a significant inverse association with advanced fibrosis in the USA population study, the ability to physical activity alone to improve liver fibrosis needs further study. ${ }^{137,45}$ Therefore, current AASLD and EASL guidelines recommend a combination of a hypocaloric diet with moderate-intensity physical activity to achieve and maintain weight loss over time.,20

\section{Pharmacological strategy}

Several pharmacological therapies may have cardioprotective effects in individuals with NAFLD, including anti-diabetic medications, lipid-lowering medication, antioxidants, semi-synthetic bile acid analogs (obeticholic acid), aspirin, and renin-angiotensin system (RAS) inhibitors. ${ }^{1,20,46}$ Table 1 summarizes the potential effects of each medication on improvement in NASH, hepatic fibrosis, and reduction of the CVD risk.

Anti-diabetic medications which may have the potential cardioprotective effects in patients with NAFLD include metformin, thiazolidinedione, glucagon-like peptide 1 (GLP-1) receptor agonists, and sodium-glucose cotransporter type-2 (SGLT-2) inhibitors. ${ }^{1,20,46,47}$ Recent studies reported that metformin use was associated with lower CVD and CVD-related mortality in patients with and without diabetes. ${ }^{48,49}$ However, metformin has not been shown to improve NASH or liver fibrosis. ${ }^{50,51}$ Therefore, current guidelines do not recommend metformin for the specific treatment of NASH. ${ }^{50,51}$

Thiazolidinediones, such as pioglitazone, are peroxisome proliferator-activated receptor agonists with insulin-sensitizing effects that have been shown to decrease the progression of liver injury and fibrosis in patients with biopsy-proven NASH irrespective of diabetes. ${ }^{1,52-54}$ The pioglitazone versus vitamin $\mathrm{E}$ versus placebo for the treatment of nondiabetic patients with NASH (PIVENS) trial demonstrated an improvement in hepatic steatosis and lobular inflammation without improvement in fibrosis scores in nondiabetic patients. ${ }^{54}$ Cusi et al. ${ }^{53}$ determined that long-term use pioglitazone, along with a hypocaloric diet, led to an improvement in metabolic and liver histology among patients with NASH and prediabetes or type 2 diabetes. In addition, a recent meta-analysis reported that pioglitazone was associated with a reduction of a major CVD event in patients with insulin resistance, prediabetes, and type 2 diabetes. ${ }^{55}$ However, it should be noted in a systemic review and meta-analysis that pioglitazone was associated with an increased risk of heart failure, weight gain, edema, and bone fractures. ${ }^{55}$ These findings of reduced major CVD events, but increased risk of heart failure with pioglitazone were corroborated by a recent large umbrella review. ${ }^{56}$ Thus, the risks and benefits of thiazolidinediones should be discussed with the patients before starting the medication.

GLP-1 agonists, such as liraglutide, have been studied in patients with NAFLD and NASH. ${ }^{57,58}$ A randomized controlled trial (phase 2) showed histological improvement and reduced fibrosis progression as well as weight loss in patients with NASH who re- 


\section{CLINCAL and MOLECULAR}

Volume_27 Number_2 April 2021

Table 1. Summary of potential interventions for nonalcoholic fatty liver disease

\begin{tabular}{|c|c|c|c|}
\hline Intervention & $\begin{array}{c}\text { Improvement of } \\
\text { nonalcoholic steatohepatitis }\end{array}$ & $\begin{array}{l}\text { Improvement of hepatic } \\
\text { fibrosis }\end{array}$ & Cardioprotective effects \\
\hline \multicolumn{4}{|l|}{ Lifestyle modification } \\
\hline Weight loss & $\sqrt{ }$ & $\sqrt{ }$ & $\sqrt{ }$ \\
\hline $\begin{array}{l}\text { Dietary modification (calorie } \\
\text { restriction, Mediterranean diet, } \\
\text { low carbohydrate diet) }\end{array}$ & $\sqrt{ }$ & $\sqrt{ }$ & $\sqrt{ }$ \\
\hline Physical activity & $\sqrt{ }$ & $\sqrt{ }$ & $\sqrt{ }$ \\
\hline \multicolumn{4}{|l|}{ Pharmacological treatment } \\
\hline Metformin & No benefit & No benefit & Potential benefit \\
\hline Thiazolidinedione & $\sqrt{ }$ & Inconclusive & $\begin{array}{c}\text { Potential benefit but increase risk of } \\
\text { heart failure }\end{array}$ \\
\hline GLP-1 receptor agonists & $\sqrt{ }$ & $\sqrt{ }$ & Potential benefit \\
\hline SGLT-2 inhibitor & $\sqrt{ }$ & $\sqrt{ }$ & Potential benefit \\
\hline DPP-4 inhibitor & Inconclusive & No benefit & No benefit \\
\hline Statins & No benefit & Inconclusive & $\sqrt{ }$ \\
\hline Omega-3-fatty acids & No benefit & No benefit & No benefit \\
\hline Vitamin E & $\sqrt{ }$ & No benefit & No benefit \\
\hline Ursodeoxycholic acid & $\sqrt{ }$ & Inconclusive & No benefit \\
\hline Obeticholic acid & $\sqrt{ }$ & $\sqrt{ }$ & $\begin{array}{l}\text { Unknown, possible increase risk of } \\
\text { CVD due to increase LDL-cholesterol }\end{array}$ \\
\hline Aspirin & Unknown & Inconclusive & $\sqrt{ }$ \\
\hline Renin-angiotensin inhibitors & Unknown & $\sqrt{ }$ & $\sqrt{ }$ \\
\hline \multicolumn{4}{|l|}{ Surgical management } \\
\hline Bariatric surgery & $\sqrt{ }$ & $\sqrt{ }$ & $\sqrt{ }$ \\
\hline
\end{tabular}

GLP-1, glucagon-like peptide 1; SGLT-2, sodium-glucose cotransporter type-2; DPP-4, dipeptidyl peptidase 4; CVD, cardiovascular disease; LDL, low-density lipoprotein.

ceived liraglutide $1.8 \mathrm{mg} /$ day for 48 weeks compared to placebo. ${ }^{58}$ A subsequent study reported that patients with uncontrolled type 2 diabetes who received liraglutide $1.2 \mathrm{mg} /$ day for 6 months had significantly reduced liver fat content. ${ }^{59}$ Moreover, liraglutide has been demonstrated to be associated with a decreased risk of CVD and cardiovascular mortality in type 2 diabetes. ${ }^{60,61}$ Although the current AASLD guideline suggests that it is premature to consider GLP-1 agonists for the treatment of NASH or NAFLD, ${ }^{1}$ emerging evidence has suggested a cardioprotective effect of liraglutide in type 2 diabetes. ${ }^{60,61}$ Therefore, GLP-1 agonists may be considered for the treatment of diabetes in patients with NAFLD given its associated cardioprotective effect.

SGLT-2 inhibitors represent another pharmacologic option. A recent meta-analysis showed that SGLT-2 inhibitors are associated with the improvement of results of blood tests for liver function, hepatic fat content, and hepatic fibrosis in patients with type 2 diabetes with NAFLD. ${ }^{62}$ In addition, studies also supported the cardioprotective effect of SGLT-2 inhibitors in patients with type 2 diabetes. ${ }^{63,64}$ Current guidelines did not provide any recommendations for SGLT-2 inhibitors use for the treatment of NASH or NAFLD. ${ }^{1,20,25}$ Further studies are warranted to investigate the cardioprotective effect of long-term SGLT-2 inhibitors use in patients with NAFLD. It should be noted that SGLT-2 inhibitors are associated with the genitourinary tract infections, and less frequent adverse events, such as diarrhea, acute kidney injury, and bone fractures. $^{65}$

Dipeptidyl peptidase 4 (DPP-4) inhibitors, such as sitagliptin, were evaluated among patients with NAFLD. Several studies demonstrated that patients with type 2 diabetes and NASH who received sitagliptin showed improvement in results of blood tests for liver function, parameters in diabetes, liver fat content, and liver histology. ${ }^{66,67}$ However, there have been some conflicting re- 
sults on the impact of DPP-4 inhibitors use on liver histology. In a small placebo-controlled trial in 12 patients with biopsy-proven NASH, there was no improvement of hepatic fibrosis or liver histology after 24 weeks of sitagliptin therapy. ${ }^{68}$ However, a subsequent randomized controlled trial showed that one year of sitagliptin $100 \mathrm{mg}$ daily in patients with NASH led to an improvement in liver histology and hepatocyte ballooning, but without any change in fibrosis scores; these improvements were noted irrespective of diabetes. ${ }^{69}$ Studies suggested that sitagliptin could be safely used in type 2 diabetes and not associated with an increased risk of major adverse CVD events nor was it associated improved CVD outcomes. ${ }^{70,71}$ In a comparative cohort study, initiation of SGLT-2 inhibitors was associated with lower risks of heart failure, myocardial infarction, and stroke compared to initiation of DPP-4 inhibitors. ${ }^{72}$ Current guidelines did not discuss the role of DPP-4 inhibitors in patients with NASH or NAFLD, but given the associated cardioprotective effect with other agents, such as SGLT-2 inhibitors, for the treatment of diabetes, clinicians should consider favoring anti-diabetic agents with associated cardioprotective effects in patients with NAFLD.

Despite the fact that statins are approved for primary prevention of CVD in high-risk patients given the well-known protective effects against CVD, there is insufficient evidence to recommend statin use for the treatment of liver disease in individuals with NAFLD. ${ }^{73,74}$ Despite inconsistent results regarding improvement in liver histology and liver chemistries in patients with $\mathrm{NASH}_{1}{ }^{75-79}$ statins use has been demonstrated to improve surrogate markers of serum lipids for CVD prevention. ${ }^{80}$ Statins have been known to be safe for the treatment of dyslipidemia in patients with NAFLD or NASH but should be avoided in patients with decompensated cirrhosis due to NASH. ${ }^{1,20,81}$ At present, given that the high risk of CVD mortality in patients with NASH or NAFLD, the benefits of statins use for the treatment of dyslipidemia outweigh the risk for adverse effects from statins and should be considered in the treatment of dyslipidemia. ${ }^{1,20}$

Omega-3 fatty acids are approved for the treatment of hypertriglyceridemia but are not currently recommended for treatment of NAFLD or NASH ${ }^{1,20,82,83}$ or for primary prevention of CVD. ${ }^{84,85}$

AASLD guidelines recommend considering vitamin E $800 \mathrm{IU}$ per day for nondiabetic biopsy-proven NASH without cirrhosis after discussing the risk and benefit of the medication based on the PIVENS trial. ${ }^{1,54}$ At present, there is no strong evidence evaluating the cardioprotective effect of vitamin $E$ in patients with NAFLD. In the general population, there is no evidence for reduced CVD risk associated with vitamin E supplementation. ${ }^{86,87}$ Ursodeoxycholic acid (UDCA) was not recommended by the current guideline for the treatment of NASH since several large multicenter trials showed no histologic benefit over placebo. ${ }^{1,20,88}$ Similar to vitamin $\mathrm{E}$, further studies are warranted to investigate the possible cardioprotective effect of UDCA specifically in patients with NAFLD.

Obeticholic acid is a promising agent for the treatment of NASH. A recent multicenter randomized controlled phase 3 trial reported that patients with NASH who received obeticholic acid $25 \mathrm{mg}$ daily had significant improvement in hepatic fibrosis, histology, and key components of disease activity in NASH. ${ }^{89}$ It should be noted that obeticholic acid is associated with adverse events, including dose-related pruritus, elevated total cholesterol, and low-density lipoprotein (LDL) cholesterol level, some of which are postulated to be transient given elevated LDL cholesterol levels at 1 month, then approached baseline at 18 months. However, further studies are warranted to determine the real-world impact of obeticholic acid on the risk of CVD, especially given the undesirable effect of obeticholic acid on the lipid profile in patients with NAFLD.

Currently, there are no randomized controlled trials regarding the cardioprotective effect of aspirin, especially in patients with NASH or NAFLD. Observational studies with biopsy-proven NAFLD have shown that daily aspirin use was associated with less severe histologic features of NASH and fibrosis, and daily aspirin users had a significantly lower risk for developing advanced fibrosis, which appeared to be duration dependent. ${ }^{90,91}$ Current guidelines do not provide any recommendations regarding daily aspirin use in patients with NAFLD. Further longitudinal studies are required to determine the cardioprotective effect and hepatoprotective effect of aspirin in patients with NASH.

A meta-analysis study of four trials of 210 patients with advanced fibrosis due to multiple etiologies showed that RAS inhibitor use is associated with a reduction in hepatic fibrosis scores and area of fibrosis; however, high-quality large randomized controlled trials are required to confirm these findings. ${ }^{92}$ Current AASLD guidance does not discuss the role of RAS inhibitors for the treatment of NAFLD. Further studies are needed to investigate the effect of RAS inhibitors on liver histology and fibrosis as well as CVD risk among patients with NAFLD.

\section{Surgical management strategy}

Bariatric surgery is an option for patients with NASH who remain unresponsive to lifestyle and pharmacological management. ${ }^{1,93,94}$ Many observational studies have shown an improve- 
ment in histology and fibrosis in patients with NASH following bariatric surgery. ${ }^{95-97}$ A prospective study of 109 patients with NASH found that hepatic fibrosis improved in 33\% of patients, and $85 \%$ of patients had NASH resolution at a 1-year follow-up liver biopsy. ${ }^{97} \mathrm{~A}$ meta-analysis showed that bariatric surgery results in the resolution of steatosis (66\%), lobular inflammation (50\%), and fibrosis (40\%) in patients with NAFLD. ${ }^{93}$ Previous studies have shown a lower risk of CVD events and incident heart failure in patients who underwent bariatric surgery. ${ }^{98,99}$ Further studies are needed to investigate whether bariatric surgery has a potential cardioprotective effect in the setting of NAFLD or NASH.

In summary, patients with NASH or NAFLD should be screened for risk factors associated with CVD, such as abdominal obesity, diabetes, dyslipidemia, metabolic syndrome, and hypertension, and initiate early treatment to prevent CVD complications. Early lifestyle modifications (7-10\% of body weight loss, dietary changes, and increasing physical activity) remain the cornerstone for primary and secondary prevention of CVD. Monitoring fasting blood glucose, hemoglobin A1c, blood pressure, and lipid profiles in patients with NAFLD has been proposed in previous literature. ${ }^{7,100}$ Based on the current AASLD guidelines, statins can be used for the treatment of dyslipidemia in patients with NAFLD and NASH, but there is no approved medication for the treatment of NASH to prevent CVD. ${ }^{1,20}$ In terms of surgical interventions, bariatric surgery has been shown to improve liver histology and fibrosis in NASH. ${ }^{93}$ However, long-term outcome studies are needed to investigate the impact of bariatric surgery on CVD risk reduc- tion among patients with NAFLD or NASH.

\section{TYPE 2 DIABETES MELLITUS}

NAFLD has been shown to be an independent risk factor for type 2 diabetes mellitus. NAFLD and type 2 diabetes share several pathophysiologic backgrounds, including obesity, insulin resistance, and metabolic syndrome. ${ }^{1,6} \mathrm{~A}$ study evaluating the association between NASH and insulin resistance showed that most patients with NASH have insulin resistance and that the association between NASH and insulin resistance is independent of obesity. ${ }^{101}$ A recent meta-analysis demonstrated the high global prevalence of NAFLD (55\%; 95\% Cl, 47.3-63.7\%) and NASH (37.3\%; 95\% $\mathrm{Cl}, 24.7-50.0 \%)$ in patients with type 2 diabetes. ${ }^{102}$ Advanced fibrosis in patients with NAFLD and type 2 diabetes is approximately $17 \%(95 \% \mathrm{Cl}, 7.2-34.8 \%)^{102}$ In addition, a meta-analysis demonstrated the increased incidence of type 2 diabetes in patients with NAFLD with a pooled HR of $2.22(95 \% \mathrm{Cl}, 1.84-2.60))^{103}$ However, it should be noted that NAFLD and type 2 diabetes have a bidirectional relationship and can develop simultaneously, which can confound the prevalence of NAFLD in type 2 diabetes. ${ }^{1}$ This emphasizes the importance of increased awareness of the association between NAFLD and type 2 diabetes to all important stakeholders, including primary care physicians, specialists, and policymakers. The current AASLD guidance states that noninvasive fibrosis imaging, such as vibration-controlled transient elastogra-

Table 2. Summary of potential treatment strategy for extrahepatic manifestations in nonalcoholic fatty liver disease

\begin{tabular}{|c|c|c|c|}
\hline Extrahepatic manifestations & $\begin{array}{l}\text { Behavioral intervention (weight loss, } \\
\text { diet restriction, physical activity) }\end{array}$ & Pharmacological treatment & Bariatric surgery \\
\hline Cardiovascular disease & $\sqrt{ }$ & Possible aspirin, statins, RAS inhibitor & Potential benefit \\
\hline Type 2 diabetes mellitus & $\sqrt{ }$ & $\begin{array}{l}\text { Diabetic medication (metformin, } \\
\text { thiazolidinedione, GLP-1 agonist, SGLT-2 } \\
\text { inhibitor, DPP-4 inhibitor), aspirin, statins }\end{array}$ & $\sqrt{ }$ \\
\hline Metabolic syndrome & $\sqrt{ }$ & Possible statins & No indication \\
\hline Hypertension & $\sqrt{ }$ & Possible RAS inhibitors & No indication \\
\hline Chronic kidney disease & $\sqrt{ }$ & Possible RAS inhibitors & No indication \\
\hline Extrahepatic malignancy & $\sqrt{ }$ & No indication & No indication \\
\hline Obstructive sleep apnea & $\sqrt{ }$ & No indication & No indication \\
\hline Hypothyroidism & $\sqrt{ }$ & Thyroid replacement therapy & No indication \\
\hline Polycystic ovarian syndrome & $\sqrt{ }$ & Metformin & No indication \\
\hline Psoriasis & $\sqrt{ }$ & Possible TNF-inhibitor (etanercept) & No indication \\
\hline
\end{tabular}

RAS, renin-angiotensin system; GLP-1, glucagon-like peptide 1; SGLT-2, sodium-glucose cotransporter type-2; DPP-4, dipeptidyl peptidase 4; TNF, tumor necrosis factor. 
phy, can be used to stratify patients with NAFLD as low or high risk for advanced fibrosis.' At this time, routine screening for NAFLD in patients with type 2 diabetes is not advised due to the uncertainty of diagnostic tests and treatment options and the lack of evidence to support long-term benefits with cost-effective screening. ${ }^{1}$ However, given the increased risk of type 2 diabetes in patients with NAFLD, annual screening for type 2 diabetes with glycosylated hemoglobin or oral glucose tolerance test was proposed in a recent study. ${ }^{104} \mathrm{~A}$ study suggests that NAFLD screening in individuals with type 2 diabetes may be potentially valuable and cost-effective. ${ }^{105}$ The treatment strategy for type 2 diabetes in patients with NAFLD is summarized in Table 2.

\section{CHRONIC KIDNEY DISEASE (CKD)}

Several studies demonstrated that NAFLD was independently associated with the risk of CKD regardless of cardiorenal risk factors status such as obesity, hypertension, or type 2 diabetes. ${ }^{106-112}$ In a systematic review and meta-analysis, the severity of NAFLD was associated with an increased risk and severity of CKD, which remained significant in diabetic and nondiabetic populations as well as in studies that adjusted for typical CKD risk factors. ${ }^{113}$ Moreover, a recent meta-analysis demonstrated a significantly increased risk of albuminuria in patients with NAFLD, which can predispose to CKD. ${ }^{114} \mathrm{~A}$ recent review article summarized potential mechanisms between NAFLD and CKD, such as shared risk factors (type 2 diabetes, metabolic syndrome, obesity, hypertension), perturbation of the intestinal microbiota, prothrombotic state, platelet activation, and increased uric acid levels. ${ }^{110}$ The current guidelines did not address the management of CKD in patients with NAFLD or NASH. ${ }^{1,20}$ Some experts have proposed a potential screening strategy, which includes yearly urine microalbumin, albumin/creatinine ratio, and glomerular filtration rates in patients with NAFLD or NASH for early detection of CKD especially those with comorbid conditions, such as type 2 diabetes and obesity; however, there is insufficient evidence to establish formal guidelines for screening CKD in patients with NAFLD. ${ }^{100}$

\section{EXTRAHEPATIC MALIGNANCY}

Extrahepatic malignancy-related mortality has been shown to be among the top three common causes of death in patients with NAFLD or NASH. ${ }^{10,115}$ A recent study based on the USA national mortality database showed that hematologic and solid cancer-related mortality among subjects with NAFLD had significantly increased in the recent decade." A recent longitudinal cohort study demonstrated that NAFLD was associated with a higher risk of extrahepatic malignancy including uterine cancer (incidence rate ratio [IRR], 2.3; 95\% Cl, 1.4-4.1), gastric cancer (IRR, 1.8; 95\% $\mathrm{Cl}, 1.3-4.1)$, pancreatic cancer (IRR, 2.0; 95\% Cl, 1.2-3.3), and colon cancer (IRR, 1.8; 95\% Cl, 1.1-2.8) after 21 years of follow up. ${ }^{116}$ NAFLD was associated with an estimated 2-fold increased risk of malignancy, especially within the liver, gastrointestinal tract, and uterus. ${ }^{116}$ In a systematic review and meta-analysis, NAFLD was associated with various extrahepatic malignancies, colorectal cancer (pooled odds ratio [OR], 1.72; $95 \% \mathrm{Cl}, 1.40$ 2.11), colorectal adenoma (pooled $\mathrm{OR}, 1.37 ; 95 \% \mathrm{Cl}, 1.29-1.46$ ), intrahepatic cholangiocarcinoma (pooled OR, 2.46; 95\% Cl, 1.77-3.44), extrahepatic cholangiocarcinoma (pooled OR, 2.24; $95 \% \mathrm{Cl}, 1.58-3.17$ ), and gastric cancer (pooled OR, 1.74; 95\% Cl, 1.03-2.95). ${ }^{117}$ Given this data, clinicians should be aware of the concern for increased risk of extrahepatic malignancy in patients with NAFLD. Physicians should emphasize that patients with NAFLD are up to date with their cancer surveillance, including coIon cancer and breast cancer surveillance based on current guidelines. Patients should be counseled regarding behaviors that may be associated with an increased cancer risk, such as heavy alcohol consumption and smoking.

\section{OBSTRUCTIVE SLEEP APNEA (OSA)}

OSA has been shown to be correlated with the presence of NAFLD and severity of NAFLD, including lobular inflammation, ballooning degeneration, and fibrosis. ${ }^{118-120}$ A recent study demonstrated an increased prevalence of NAFLD in patients with OSA, even in the absence of obesity or metabolic syndrome. ${ }^{120}$ The data on the association between OSA and fibrosis are mixed. The degree of hypoxic burden due to OSA is associated with increased fibrosis. ${ }^{118,121,122}$ However, in a cohort of nearly 1,300 subjects with suspected OSA, the associated risk of hepatic fibrosis was not significant in the multivariate model. ${ }^{123}$ There are some evidences that the treatment of OSA with continuous positive airway pressure is associated with significant biochemical improvement and reduction in NAFLD-related fibrosis. ${ }^{124}$

Despite these associations between OSA and NAFLD, there are no guidelines for screening for OSA in the setting of NAFLD. A recent review by Mesarwi et al., ${ }^{118}$ proposed screening patients with 


\section{CLINICAL and MOLECULAR}

NAFLD for OSA, because a large proportion of those with OSA are relatively asymptomatic. Further studies are required to assess the utility and cost-effectiveness for screening all patients with NAFLD for OSA. In general, behavioral modifications to promote weight loss are key, given the associated improvement in OSA severity and reduced upper airway collapsibility, and should be strongly recommended to patients with NAFLD and OSA. ${ }^{125,126}$

\section{HYPOTHYROIDISM}

Subclinical hypothyroidism or overt hypothyroidism is associated with an increased risk of NAFLD compared to euthyroid individuals. ${ }^{127-131}$ Low thyroid function within euthyroid individuals was significantly associated with NASH and advanced fibrosis. ${ }^{128,132} \mathrm{~A}$ recent study based on the USA population-based study documented that low thyroid function was associated with a higher risk for overall and cardiovascular mortality in individuals with NAFLD. ${ }^{133}$ The mechanism between hypothyroidism and NAFLD is thought to be related to increases in reactive oxygen species, leptin hormone, and fibroblast growth factor-21, which lead to hepatic insulin resistance and NAFLD. ${ }^{130,131}$ Currently, resmetirom (MGL-3196), an orally active, liver-directed, selective thyroid hormone receptor-beta agonist, is a potential drug for the treatment of NASH and hyperlipidemia. ${ }^{134,135}$ A recent randomized, placebocontrolled phase 2 trial reported that resmetirom resulted in a significant reduction in hepatic fat content after 12 weeks and 36 weeks of treatment among patients with NASH. ${ }^{136}$ Currently, there is insufficient evidence that screening hypothyroidism in individuals with NAFLD is cost-effective. However, physicians should be aware of the association between NAFLD and hypothyroidism because hypothyroidism is a modifiable risk factor. In a review by VanWagner and Rinella, ${ }^{100}$ screening for thyroid dysfunction is recommended in patients with $\mathrm{NASH}$.

\section{POLYCYSTIC OVARIAN SYNDROME (PCOS)}

PCOS is a common endocrinopathy in reproductive women that is associated with insulin resistance, elevated androgens, and

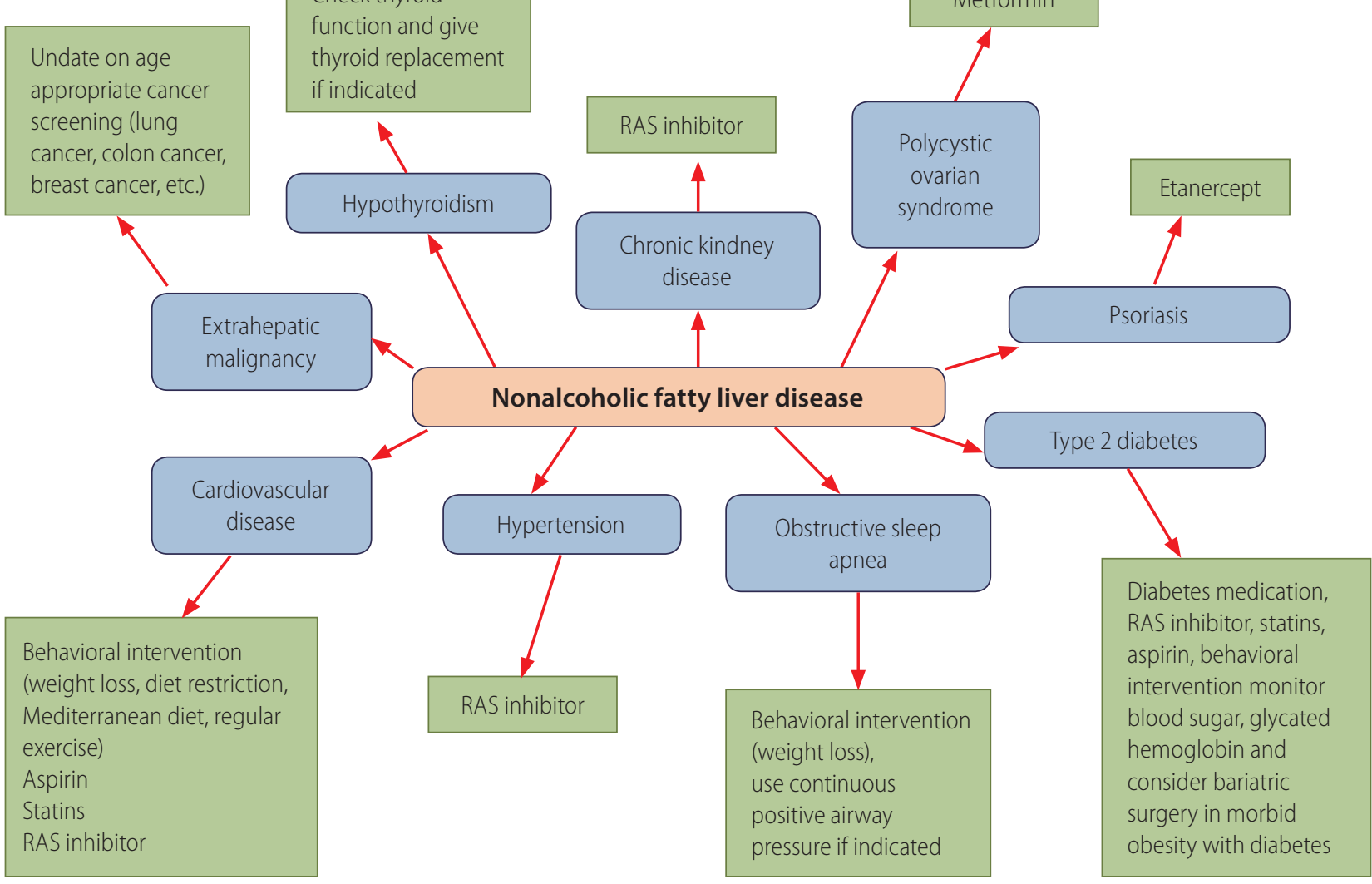

Figure 1. Evaluation and management of extrahepatic manifestations of nonalcoholic fatty liver disease. RAS, renin-angiotensin system. 
other metabolic comorbidities. ${ }^{137}$ A recent meta-analysis showed that patients with PCOS had an approximately 3-fold higher risk of NAFLD independent of obesity status. ${ }^{138}$ Hyperandrogenism was a risk factor for nonobese NAFLD independent of obesity, lipid profile, insulin resistance, or glycemic status, proposing a contribution of hyperandrogenism to nonobese NAFLD with PCOS. ${ }^{139}$ In a retrospective study of reproductive age women with biopsyproven NAFLD, PCOS was independently associated with more severe NASH, including advanced fibrosis. ${ }^{140}$ The mechanism behind the association is likely related to insulin resistance, which is a hallmark feature of PCOS. ${ }^{141}$ Lifestyle modifications, including weight loss, increasing physical activity, and avoiding a high-fat diet, are the cornerstones of the initial treatment for both NAFLD and PCOS. ${ }^{142}$ Metformin can be used in patients with PCOS, but it has no role in the management of NAFLD. Currently, there are no studies that demonstrate a benefit of screening for PCOS in women with NAFLD, but hepatologists should ask their reproductive age women with NAFLD about irregular menses and hirsutism, given the potential implications of undiagnosed PCOS. Further studies are warranted to investigate potential treatment options for PCOS in those with NAFLD.

\section{PSORIASIS}

Several studies have shown an increased risk of NAFLD in patients with psoriasis or psoriatic arthritis. ${ }^{133,144}$ The exact mechanism for the association remains unclear, but it is postulated that inflammatory cytokines, such as tumor necrosis factor (TNF)- $a$, play a role in the association between NAFLD and psoriasis. ${ }^{145}$ Moreover, the severity of psoriasis was also associated with an increased risk of NAFLD. ${ }^{143,144}$ In a systematic review and meta-analysis, NAFLD was associated with an increased risk for psoriasis after adjusting for comorbid risk factors. ${ }^{146} \mathrm{~A}$ case series reported 89 patients with psoriasis, metabolic syndrome, and NAFLD who received etanercept (TNF-a inhibitor) compared with psoralen-ultraviolet A treatment; those who received etanercept had a significant reduction in aspartate aminotransferase/alanine transaminase ratio, fasting insulin, homeostasis model assessment index, and C-reactive protein level. ${ }^{147}$ TNF-a inhibitors may be beneficial for psoriasis in patients with NAFLD, but larger cohort studies are warranted to confirm this finding.

\section{CONCLUSION}

NAFLD is a multisystemic disease that affects extrahepatic organ systems. Common extrahepatic manifestations in NAFLD include CVD, type 2 diabetes, metabolic syndrome, extrahepatic malignancies, CKD, hypothyroidism, PCOS, and psoriasis. Though the current guidelines do not provide guidance on the management of extrahepatic manifestation of NAFLD, the foundation of treatment for many of the extrahepatic manifestation associated with NAFLD remains lifestyle modification, including adequate weight loss, physical activity, and dietary modification (Fig. 1). Proposed screening strategies for common comorbidities in NAFLD include obtaining a fasting blood glucose, hemoglobin A1c, blood pressure, lipid profiles, estimated glomerular filtration rate, urine microalbumin and albumin creatinine ratio, and thyroid function tests; these may be considered in clinical practice to diagnose extrahepatic manifestations of NAFLD. ${ }^{100}$ Physicians should also be aware that patients with NAFLD not only have an increased risk of hepatocellular carcinoma but of extrahepatic cancers as well. Therefore, patients with NAFLD should be kept up to date on cancer screening per current recommendations (Fig. 1). Further studies are needed to investigate the effect of pharmacologic treatment on extrahepatic manifestations of NAFLD.

\section{Authors' contribution}

Dr. Karn Wijarnpreecha was involved in study concept and design, acquisition of data, drafting of the manuscript, and critical revision of the manuscript. Dr. Elizabeth $\mathrm{S}$. Aby was involved in study concept and design, acquisition of data, and drafting the manuscript. Dr. Aijaz Ahmed was involved in study concept and design, critical revision of the manuscript, and study supervision. Dr. Donghee Kim was involved in study concept and design, drafting of the manuscript, critical revision of the manuscript, and study supervision.

\section{Conflicts of Interest}

The authors have no conflicts to disclose.

\section{REFERENCES}

1. Chalasani N, Younossi Z, Lavine JE, Charlton M, Cusi K, Rinella M, et al. The diagnosis and management of nonalcoholic fatty liver disease: practice guidance from the American Association for the 
Study of Liver Diseases. Hepatology 2018;67:328-357.

2. Younossi ZM, Koenig AB, Abdelatif D, Fazel Y, Henry L, Wymer M. Global epidemiology of nonalcoholic fatty liver disease-metaanalytic assessment of prevalence, incidence, and outcomes. Hepatology 2016;64:73-84.

3. Estes C, Razavi H, Loomba R, Younossi Z, Sanyal AJ. Modeling the epidemic of nonalcoholic fatty liver disease demonstrates an exponential increase in burden of disease. Hepatology 2018;67:123133.

4. Eslam M, Sanyal AJ, George J; International Consensus Panel. MAFLD: a consensus-driven proposed nomenclature for metabolic associated fatty liver disease. Gastroenterology 2020;158:19992014.e1.

5. Younossi ZM, Rinella ME, Sanyal A, Harrison SA, Brunt E, Goodman $Z$, et al. From NAFLD to MAFLD: implications of a premature change in terminology. Hepatology 2021;73:1194-1198.

6. Byrne CD, Targher G. NAFLD: a multisystem disease. J Hepatol 2015;62(1 Suppl):S47-S64.

7. Li AA, Ahmed A, Kim D. Extrahepatic manifestations of nonalcoholic fatty liver disease. Gut Liver 2020;14:168-178.

8. Adams LA, Anstee QM, Tilg H, Targher G. Non-alcoholic fatty liver disease and its relationship with cardiovascular disease and other extrahepatic diseases. Gut 2017;66:1138-1153.

9. Angulo P, Kleiner DE, Dam-Larsen S, Adams LA, Bjornsson ES, Charatcharoenwitthaya $P$, et al. Liver fibrosis, but no other histologic features, is associated with long-term outcomes of patients with nonalcoholic fatty liver disease. Gastroenterology 2015;149:389397.e10.

10. Ekstedt $M$, Hagström $H$, Nasr P, Fredrikson $M$, Stål $P$, Kechagias $S$, et al. Fibrosis stage is the strongest predictor for disease-specific mortality in NAFLD after up to 33 years of follow-up. Hepatology 2015;61:1547-1554.

11. Kim D, Adejumo AC, Yoo ER, Iqbal U, Li AA, Pham EA, et al. Trends in mortality from extrahepatic complications in patients with chronic liver disease, from 2007 through 2017. Gastroenterology 2019;157:1055-1066.e11.

12. Targher G, Day CP, Bonora E. Risk of cardiovascular disease in patients with nonalcoholic fatty liver disease. N Engl J Med 2010;363:1341-1350.

13. Marchesini G, Bugianesi E, Forlani G, Cerrelli F, Lenzi M, Manini R, et al. Nonalcoholic fatty liver, steatohepatitis, and the metabolic syndrome. Hepatology 2003;37:917-923.

14. Targher G, Byrne CD, Lonardo A, Zoppini G, Barbui C. Non-alcoholic fatty liver disease and risk of incident cardiovascular disease: a meta-analysis. J Hepatol 2016;65:589-600.

15. Yoshitaka H, Hamaguchi M, Kojima T, Fukuda T, Ohbora A, Fukui M. Nonoverweight nonalcoholic fatty liver disease and incident cardiovascular disease: a post hoc analysis of a cohort study. Medicine
(Baltimore) 2017;96:e6712.

16. Targher G, Byrne CD, Tilg H. NAFLD and increased risk of cardiovascular disease: clinical associations, pathophysiological mechanisms and pharmacological implications. Gut 2020;69:1691-1705.

17. Kim D, Choi SY, Park EH, Lee W, Kang JH, Kim W, et al. Nonalcoholic fatty liver disease is associated with coronary artery calcification. Hepatology 2012;56:605-613.

18. Park HE, Kwak MS, Kim D, Kim MK, Cha MJ, Choi SY. Nonalcoholic fatty liver disease is associated with coronary artery calcification development: a longitudinal study. J Clin Endocrinol Metab 2016;101:3134-3143.

19. Wong CR, Lim JK. The association between nonalcoholic fatty liver disease and cardiovascular disease outcomes. Clin Liver Dis (Hoboken) 2018;12:39-44.

20. European Association for the Study of the Liver (EASL); European Association for the Study of Diabetes (EASD); European Association for the Study of Obesity (EASO). EASL-EASD-EASO clinical practice guidelines for the management of non-alcoholic fatty liver disease. J Hepatol 2016;64:1388-1402.

21. Vilar-Gomez E, Martinez-Perez Y, Calzadilla-Bertot L, TorresGonzalez A, Gra-Oramas B, Gonzalez-Fabian L, et al. Weight loss through lifestyle modification significantly reduces features of nonalcoholic steatohepatitis. Gastroenterology 2015;149:367-378.e5; quiz e14-e15.

22. Fontana L, Meyer TE, Klein S, Holloszy JO. Long-term calorie restriction is highly effective in reducing the risk for atherosclerosis in humans. Proc Natl Acad Sci U S A 2004;101:6659-6663.

23. Dyson JK, Anstee QM, McPherson S. Non-alcoholic fatty liver disease: a practical approach to treatment. Frontline Gastroenterol 2014;5:277-286.

24. Haufe S, Engeli S, Kast P, Böhnke J, Utz W, Haas V, et al. Randomized comparison of reduced fat and reduced carbohydrate hypocaloric diets on intrahepatic fat in overweight and obese human subjects. Hepatology 2011;53:1504-1514.

25. Chitturi S, Wong VW, Chan WK, Wong GL, Wong SK, Sollano J, et al. The Asia-Pacific working party on non-alcoholic fatty liver disease guidelines 2017-part 2: management and special groups. J Gastroenterol Hepatol 2018;33:86-98.

26. Chen H, Wang J, Li Z, Lam CWK, Xiao Y, Wu Q, et al. Consumption of sugar-sweetened beverages has a dose-dependent effect on the risk of non-alcoholic fatty liver disease: an updated systematic review and dose-response meta-analysis. Int J Environ Res Public Health 2019;16:2192.

27. Wijarnpreecha K, Thongprayoon C, Edmonds PJ, Cheungpasitporn W. Associations of sugar- and artificially sweetened soda with nonalcoholic fatty liver disease: a systematic review and meta-analysis. QJM 2016;109:461-466.

28. Zelber-Sagi S, Ivancovsky-Wajcman D, Fliss Isakov N, Webb M, 
Orenstein D, Shibolet $\mathrm{O}$, et al. High red and processed meat consumption is associated with nonalcoholic fatty liver disease and insulin resistance. J Hepatol 2018;68:1239-1246.

29. Noureddin M, Zelber-Sagi S, Wilkens LR, Porcel J, Boushey CJ, Le Marchand $L$, et al. Diet associations with nonalcoholic fatty liver disease in an ethnically diverse population: the multiethnic cohort. Hepatology 2020;71:1940-1952.

30. Gepner Y, Shelef I, Komy O, Cohen N, Schwarzfuchs D, Bril N, et al. The beneficial effects of Mediterranean diet over low-fat diet may be mediated by decreasing hepatic fat content. J Hepatol 2019;71:379-388.

31. Estruch R, Ros E, Salas-Salvadó J, Covas MI, Corella D, Arós F, et al. Primary prevention of cardiovascular disease with a mediterranean diet supplemented with extra-virgin olive oil or nuts. N Engl J Med 2018;378:e34.

32. Asbaghi O, Choghakhori R, Ashtary-Larky D, Abbasnezhad A. Effects of the Mediterranean diet on cardiovascular risk factors in non-alcoholic fatty liver disease patients: a systematic review and meta-analysis. Clin Nutr ESPEN 2020;37:148-156.

33. Saab S, Mallam D, Cox GA 2nd, Tong MJ. Impact of coffee on liver diseases: a systematic review. Liver Int 2014;34:495-504.

34. Nordestgaard AT, Nordestgaard BG. Coffee intake, cardiovascular disease and all-cause mortality: observational and Mendelian randomization analyses in 95 000-223000 individuals. Int J Epidemiol 2016;45:1938-1952.

35. Chen YP, Lu FB, Hu YB, Xu LM, Zheng MH, Hu ED. A systematic review and a dose-response meta-analysis of coffee dose and nonalcoholic fatty liver disease. Clin Nutr 2019;38:2552-2557.

36. Brown OI, Allgar V, Wong KY. Coffee reduces the risk of death after acute myocardial infarction: a meta-analysis. Coron Artery Dis 2016;27:566-572.

37. Kim D, Vazquez-Montesino LM, Li AA, Cholankeril G, Ahmed A. Inadequate physical activity and sedentary behavior are independent predictors of nonalcoholic fatty liver disease. Hepatology 2020;72:1556-1568.

38. Gerber L, Otgonsuren M, Mishra A, Escheik C, Birerdinc A, Stepanova $M$, et al. Nonalcoholic fatty liver disease (NAFLD) is associated with low level of physical activity: a population-based study. Aliment Pharmacol Ther 2012;36:772-781.

39. Shiroma EJ, Lee IM. Physical activity and cardiovascular health: lessons learned from epidemiological studies across age, gender, and race/ethnicity. Circulation 2010;122:743-752.

40. van der Windt DJ, Sud V, Zhang $H$, Tsung $A$, Huang $H$. The effects of physical exercise on fatty liver disease. Gene Expr 2018;18:89101.

41. Hallsworth K, Thoma C, Hollingsworth KG, Cassidy S, Anstee QM, Day $C P$, et al. Modified high-intensity interval training reduces liver fat and improves cardiac function in non-alcoholic fatty liver dis- ease: a randomized controlled trial. Clin Sci (Lond) 2015;129:10971105.

42. Lin JS, O'Connor E, Evans CV, Senger CA, Rowland MG, Groom $\mathrm{HC}$. Behavioral counseling to promote a healthy lifestyle in persons with cardiovascular risk factors: a systematic review for the U.S. Preventive Services Task Force. Ann Intern Med 2014;161:568-578.

43. Keating SE, Hackett DA, George J, Johnson NA. Exercise and nonalcoholic fatty liver disease: a systematic review and meta-analysis. J Hepatol 2012;57:157-166.

44. Kim D, Murag S, Cholankeril G, Cheung A, Harrison SA, Younossi $Z M$, et al. Physical activity, measured objectively, is associated with lower mortality in patients with nonalcoholic fatty liver disease. Clin Gastroenterol Hepatol. 2020 Jul 16. doi: 10.1016/ j.cgh.2020.07.023.

45. Thoma C, Day CP, Trenell MI. Lifestyle interventions for the treatment of non-alcoholic fatty liver disease in adults: a systematic review. J Hepatol 2012;56:255-266.

46. Ismaiel A, Dumitrascu DL. How to reduce cardiovascular risk in nonalcoholic fatty liver disease. Am J Ther. 2020 May 26. doi: 10.1097/MJT.0000000000001174.

47. Cholankeril R, Patel V, Perumpail BJ, Yoo ER, Iqbal U, Sallam S, et al. Anti-diabetic medications for the pharmacologic management of NAFLD. Diseases 2018;6:93.

48. Lexis $C P$, van der Horst-Schrivers AN, Lipsic E, Valente MA, Muller Kobold AC, de Boer RA, et al. The effect of metformin on cardiovascular risk profile in patients without diabetes presenting with acute myocardial infarction: data from the glycometabolic intervention as adjunct to primary coronary intervention in st elevation myocardial infarction (GIPS-III) trial. BMJ Open Diabetes Res Care 2015;3:e000090.

49. Griffin SJ, Leaver JK, Irving GJ. Impact of metformin on cardiovascular disease: a meta-analysis of randomised trials among people with type 2 diabetes. Diabetologia 2017;60:1620-1629.

50. Musso G, Gambino R, Cassader M, Pagano G. A meta-analysis of randomized trials for the treatment of nonalcoholic fatty liver disease. Hepatology 2010;52:79-104.

51. Li Y, Liu L, Wang B, Wang J, Chen D. Metformin in non-alcoholic fatty liver disease: a systematic review and meta-analysis. Biomed Rep 2013;1:57-64

52. Aithal GP, Thomas JA, Kaye PV, Lawson A, Ryder SD, Spendlove I, et al. Randomized, placebo-controlled trial of pioglitazone in nondiabetic subjects with nonalcoholic steatohepatitis. Gastroenterology 2008;135:1176-1184.

53. Cusi K, Orsak B, Bril F, Lomonaco R, Hecht J, Ortiz-Lopez C, et al. Long-term pioglitazone treatment for patients with nonalcoholic steatohepatitis and prediabetes or type 2 diabetes mellitus: a randomized trial. Ann Intern Med 2016;165:305-315.

54. Sanyal AJ, Chalasani N, Kowdley KV, McCullough A, Diehl AM, 
Bass NM, et al. Pioglitazone, vitamin E, or placebo for nonalcoholic steatohepatitis. N Engl J Med 2010;362:1675-1685.

55. Liao HW, Saver JL, Wu YL, Chen TH, Lee M, Ovbiagele B. Pioglitazone and cardiovascular outcomes in patients with insulin resistance, pre-diabetes and type 2 diabetes: a systematic review and meta-analysis. BMJ Open 2017;7:e013927.

56. Zhu J, Yu X, Zheng Y, Li J, Wang Y, Lin Y, et al. Association of glucose-lowering medications with cardiovascular outcomes: an umbrella review and evidence map. Lancet Diabetes Endocrinol 2020;8:192-205.

57. Armstrong MJ, Houlihan DD, Rowe IA, Clausen WH, Elbrønd B, Gough SC, et al. Safety and efficacy of liraglutide in patients with type 2 diabetes and elevated liver enzymes: individual patient data meta-analysis of the LEAD program. Aliment Pharmacol Ther 2013;37:234-242.

58. Armstrong MJ, Gaunt P, Aithal GP, Barton D, Hull D, Parker R, et al. Liraglutide safety and efficacy in patients with non-alcoholic steatohepatitis (LEAN): a multicentre, double-blind, randomised, placebo-controlled phase 2 study. Lancet 2016;387:679-690.

59. Petit JM, Cercueil JP, Loffroy R, Denimal D, Bouillet B, Fourmont C, et al. Effect of liraglutide therapy on liver fat content in patients with inadequately controlled type 2 diabetes: the lira-NAFLD study. J Clin Endocrinol Metab 2017;102:407-415.

60. Svanström H, Ueda P, Melbye M, Eliasson B, Svensson AM, Franzén $S$, et al. Use of liraglutide and risk of major cardiovascular events: a register-based cohort study in Denmark and Sweden. Lancet Diabetes Endocrinol 2019;7:106-114.

61. Howell R, Wright AM, Clements JN. Clinical potential of liraglutide in cardiovascular risk reduction in patients with type 2 diabetes: evidence to date. Diabetes Metab Syndr Obes 2019;12:505-512.

62. Raj H, Durgia H, Palui R, Kamalanathan S, Selvarajan S, Kar SS, et al. SGLT-2 inhibitors in non-alcoholic fatty liver disease patients with type 2 diabetes mellitus: a systematic review. World J Diabetes 2019;10:114-132.

63. Rabizadeh S, Nakhjavani M, Esteghamati A. Cardiovascular and renal benefits of SGLT2 inhibitors: a narrative review. Int J Endocrinol Metab 2019;17:e84353.

64. Arnott C, Li Q, Kang A, Neuen BL, Bompoint S, Lam CSP, et al. Sodium-glucose cotransporter 2 inhibition for the prevention of cardiovascular events in patients with type 2 diabetes mellitus: a systematic review and meta-analysis. J Am Heart Assoc 2020;9:e014908.

65. Singh M, Kumar A. Risks associated with SGLT2 inhibitors: an overview. Curr Drug Saf 2018;13:84-91.

66. Yilmaz Y, Yonal O, Deyneli O, Celikel CA, Kalayci C, Duman DG. Effects of sitagliptin in diabetic patients with nonalcoholic steatohepatitis. Acta Gastroenterol Belg 2012;75:240-244.

67. Iwasaki T, Yoneda M, Inamori M, Shirakawa J, Higurashi T, Maeda S, et al. Sitagliptin as a novel treatment agent for non-alcoholic fatty liver disease patients with type 2 diabetes mellitus. Hepatogastroenterology 2011;58:2103-2105.

68. Joy TR, McKenzie CA, Tirona RG, Summers K, Seney S, Chakrabarti $S$, et al. Sitagliptin in patients with nonalcoholic steatohepatitis: a randomized, placebo-controlled trial. World J Gastroenterol 2017;23:141-150.

69. Alam S, Ghosh J, Mustafa G, Kamal M, Ahmad N. Effect of sitagliptin on hepatic histological activity and fibrosis of nonalcoholic steatohepatitis patients: a 1-year randomized control trial. Hepat Med 2018;10:23-31.

70. Green JB, Bethel MA, Armstrong PW, Buse JB, Engel SS, Garg J, et al. Effect of sitagliptin on cardiovascular outcomes in type 2 diabetes. N Engl J Med 2015;373:232-242.

71. Khalse M, Bhargava A. A review on cardiovascular outcome studies of dipeptidyl peptidase-4 inhibitors. Indian J Endocrinol Metab 2018;22:689-695.

72. Kohsaka S, Lam CSP, Kim DJ, Cavender MA, Norhammar A, Jørgensen ME, et al. Risk of cardiovascular events and death associated with initiation of SGLT2 inhibitors compared with DPP-4 inhibitors: an analysis from the CVD-REAL 2 multinational cohort study. Lancet Diabetes Endocrinol 2020;8:606-615.

73. Athyros VG, Alexandrides TK, Bilianou H, Cholongitas E, Doumas M, Ganotakis ES, et al. The use of statins alone, or in combination with pioglitazone and other drugs, for the treatment of nonalcoholic fatty liver disease/nonalcoholic steatohepatitis and related cardiovascular risk. An expert panel statement. Metabolism 2017;71:17-32.

74. Arnett DK, Blumenthal RS, Albert MA, Buroker AB, Goldberger ZD, Hahn EJ, et al. 2019 ACC/AHA guideline on the primary prevention of cardiovascular disease: executive summary: a report of the American College of Cardiology/American Heart Association task force on clinical practice guidelines. J Am Coll Cardiol 2019;74:1376-1414.

75. Hyogo H, Tazuma S, Arihiro K, Iwamoto K, Nabeshima Y, Inoue $M$, et al. Efficacy of atorvastatin for the treatment of nonalcoholic steatohepatitis with dyslipidemia. Metabolism 2008;57:1711-1718.

76. Ekstedt M, Franzén LE, Mathiesen UL, Holmqvist M, Bodemar G, Kechagias S. Statins in non-alcoholic fatty liver disease and chronically elevated liver enzymes: a histopathological follow-up study. J Hepatol 2007;47:135-141.

77. Kimura Y, Hyogo H, Yamagishi S, Takeuchi M, Ishitobi T, Nabeshima $Y$, et al. Atorvastatin decreases serum levels of advanced glycation endproducts (AGEs) in nonalcoholic steatohepatitis (NASH) patients with dyslipidemia: clinical usefulness of AGEs as a biomarker for the attenuation of NASH. J Gastroenterol 2010;45:750-757.

78. Foster T, Budoff MJ, Saab S, Ahmadi N, Gordon C, Guerci AD. Atorvastatin and antioxidants for the treatment of nonalcoholic 
fatty liver disease: the St Francis Heart Study randomized clinical trial. Am J Gastroenterol 2011;106:71-77.

79. Lewis JH, Mortensen ME, Zweig S, Fusco MJ, Medoff JR, Belder $R$, et al. Efficacy and safety of high-dose pravastatin in hypercholesterolemic patients with well-compensated chronic liver disease: results of a prospective, randomized, double-blind, placebocontrolled, multicenter trial. Hepatology 2007;46:1453-1463.

80. Sigler MA, Congdon L, Edwards KL. An evidence-based review of statin use in patients with nonalcoholic fatty liver disease. Clin Med Insights Gastroenterol 2018;11:1179552218787502.

81. Tzefos M, Olin JL. 3-hydroxyl-3-methylglutaryl coenzyme A reductase inhibitor use in chronic liver disease: a therapeutic controversy. J Clin Lipidol 2011;5:450-459.

82. Sanyal AJ, Abdelmalek MF, Suzuki A, Cummings OW, Chojkier M; EPE-A Study Group. No significant effects of ethyl-eicosapentanoic acid on histologic features of nonalcoholic steatohepatitis in a phase 2 trial. Gastroenterology 2014;147:377-384.e1.

83. Argo CK, Patrie JT, Lackner C, Henry TD, de Lange EE, Weltman $A L$, et al. Effects of $n-3$ fish oil on metabolic and histological parameters in NASH: a double-blind, randomized, placebo-controlled trial. J Hepatol 2015;62:190-197.

84. Lan M, Nguyen T, Gray S. Omega-3 fatty acid supplements for the prevention of cardiovascular disease. Sr Care Pharm 2020;35:318323.

85. Bowen KJ, Harris WS, Kris-Etherton PM. Omega-3 fatty acids and cardiovascular disease: are there benefits? Curr Treat Options Cardiovasc Med 2016;18:69.

86. Myung SK, Ju W, Cho B, Oh SW, Park SM, Koo BK, et al. Efficacy of vitamin and antioxidant supplements in prevention of cardiovascular disease: systematic review and meta-analysis of randomised controlled trials. BMJ 2013;346:f10.

87. Vivekananthan DP, Penn MS, Sapp SK, Hsu A, Topol EJ. Use of antioxidant vitamins for the prevention of cardiovascular disease: meta-analysis of randomised trials. Lancet 2003;361:2017-2023.

88. Lindor KD, Kowdley KV, Heathcote EJ, Harrison ME, Jorgensen $\mathrm{R}$, Angulo $\mathrm{P}$, et al. Ursodeoxycholic acid for treatment of nonalcoholic steatohepatitis: results of a randomized trial. Hepatology 2004;39:770-778

89. Younossi ZM, Ratziu V, Loomba R, Rinella M, Anstee QM, Goodman $Z$, et al. Obeticholic acid for the treatment of non-alcoholic steatohepatitis: interim analysis from a multicentre, randomised, placebo-controlled phase 3 trial. Lancet 2019;394:2184-2196.

90. Simon TG, Henson J, Osganian S, Masia R, Chan AT, Chung RT, et al. Daily aspirin use associated with reduced risk for fibrosis progression in patients with nonalcoholic fatty liver disease. Clin Gastroenterol Hepatol 2019;17:2776-2784.e4.

91. Jiang ZG, Feldbrügge L, Tapper EB, Popov Y, Ghaziani T, Afdhal $\mathrm{N}$, et al. Aspirin use is associated with lower indices of liver fibro- sis among adults in the United States. Aliment Pharmacol Ther 2016:43:734-743.

92. Zhu Q, Li N, Li F, Zhou Z, Han Q, Lv Y, et al. Therapeutic effect of renin angiotensin system inhibitors on liver fibrosis. J Renin Angiotensin Aldosterone Syst 2016;17:1470320316628717.

93. Lee Y, Doumouras AG, Yu J, Brar K, Banfield L, Gmora S, et al. Complete resolution of nonalcoholic fatty liver disease after bariatric surgery: a systematic review and meta-analysis. Clin Gastroenterol Hepatol 2019;17:1040-1060.e11.

94. Klebanoff MJ, Corey KE, Chhatwal J, Kaplan LM, Chung RT, Hur C. Bariatric surgery for nonalcoholic steatohepatitis: a clinical and cost-effectiveness analysis. Hepatology 2017;65:1156-1164.

95. Mathurin P, Hollebecque A, Arnalsteen L, Buob D, Leteurtre E, Caiazzo $R$, et al. Prospective study of the long-term effects of bariatric surgery on liver injury in patients without advanced disease. Gastroenterology 2009;137:532-540.

96. Laursen TL, Hagemann CA, Wei C, Kazankov K, Thomsen KL, Knop $F K$, et al. Bariatric surgery in patients with non-alcoholic fatty liver disease - from pathophysiology to clinical effects. World J Hepatol 2019;11:138-149.

97. Lassailly G, Caiazzo R, Buob D, Pigeyre M, Verkindt H, Labreuche J, et al. Bariatric surgery reduces features of nonalcoholic steatohepatitis in morbidly obese patients. Gastroenterology 2015;149:379388; quiz e15-e16.

98. Moussa O, Ardissino M, Heaton T, Tang A, Khan O, Ziprin P, et al. Effect of bariatric surgery on long-term cardiovascular outcomes: a nationwide nested cohort study. Eur Heart J 2020;41:2660-2667.

99. Benraouane $F$, Litwin SE. Reductions in cardiovascular risk after bariatric surgery. Curr Opin Cardiol 2011;26:555-561.

100. VanWagner LB, Rinella ME. Extrahepatic manifestations of nonalcoholic fatty liver disease. Curr Hepatol Rep 2016;15:75-85.

101. Chitturi S, Abeygunasekera S, Farrell GC, Holmes-Walker J, Hui $J M$, Fung $C$, et al. NASH and insulin resistance: insulin hypersecretion and specific association with the insulin resistance syndrome. Hepatology 2002;35:373-379.

102. Younossi ZM, Golabi P, de Avila L, Paik JM, Srishord M, Fukui N, et al. The global epidemiology of NAFLD and NASH in patients with type 2 diabetes: a systematic review and meta-analysis. J Hepatol 2019;71:793-801.

103. Mantovani A, Byrne CD, Bonora E, Targher G. Nonalcoholic fatty liver disease and risk of incident type 2 diabetes: a meta-analysis. Diabetes Care 2018;41:372-382.

104. Armstrong MJ, Adams LA, Canbay A, Syn WK. Extrahepatic complications of nonalcoholic fatty liver disease. Hepatology 2014;59: 1174-1197.

105. Noureddin M, Jones C, Alkhouri N, Gomez EV, Dieterich DT, Rinella $M E$, et al. Screening for nonalcoholic fatty liver disease in persons with type 2 diabetes in the United States is cost-effective: a com- 
prehensive cost-utility analysis. Gastroenterology 2020;159:19851987.

106. Targher G, Chonchol M, Zoppini G, Abaterusso C, Bonora E. Risk of chronic kidney disease in patients with non-alcoholic fatty liver disease: is there a link? J Hepatol 2011;54:1020-1029.

107. Targher G, Bertolini L, Rodella S, Lippi G, Zoppini G, Chonchol $M$. Relationship between kidney function and liver histology in subjects with nonalcoholic steatohepatitis. Clin J Am Soc Nephrol 2010;5:2166-2171.

108. Targher G, Bertolini L, Rodella S, Zoppini G, Lippi G, Day C, et al. Non-alcoholic fatty liver disease is independently associated with an increased prevalence of chronic kidney disease and proliferative/ laser-treated retinopathy in type 2 diabetic patients. Diabetologia 2008;51:444-450.

109. Kaps L, Labenz C, Galle PR, Weinmann-Menke J, Kostev K, Schattenberg JM. Non-alcoholic fatty liver disease increases the risk of incident chronic kidney disease. United European Gastroenterol J 2020;8:942-948.

110. Byrne CD, Targher G. NAFLD as a driver of chronic kidney disease. J Hepatol 2020;72:785-801.

111. Marcuccilli M, Chonchol M. NAFLD and chronic kidney disease. Int J Mol Sci 2016;17:562.

112. Jang HR, Kang D, Sinn DH, Gu S, Cho SJ, Lee JE, et al. Nonalcoholic fatty liver disease accelerates kidney function decline in patients with chronic kidney disease: a cohort study. Sci Rep 2018;8:4718.

113. Musso G, Gambino R, Tabibian JH, Ekstedt M, Kechagias S, Hamaguchi $\mathrm{M}$, et al. Association of non-alcoholic fatty liver disease with chronic kidney disease: a systematic review and meta-analysis. PLoS Med 2014;11:e1001680.

114. Wijarnpreecha K, Thongprayoon C, Boonpheng B, Panjawatanan $P$, Sharma K, Ungprasert $P$, et al. Nonalcoholic fatty liver disease and albuminuria: a systematic review and meta-analysis. Eur J Gastroenterol Hepatol 2018;30:986-994.

115. Paik JM, Henry L, De Avila L, Younossi E, Racila A, Younossi ZM. Mortality related to nonalcoholic fatty liver disease is increasing in the United States. Hepatol Commun 2019;3:1459-1471.

116. Allen AM, Hicks SB, Mara KC, Larson JJ, Therneau TM. The risk of incident extrahepatic cancers is higher in non-alcoholic fatty liver disease than obesity - a longitudinal cohort study. J Hepatol 2019;71:1229-1236.

117. Liu SS, Ma XF, Zhao J, Du SX, Zhang J, Dong MZ, et al. Association between nonalcoholic fatty liver disease and extrahepatic cancers: a systematic review and meta-analysis. Lipids Health Dis 2020;19:118.

118. Mesarwi OA, Loomba R, Malhotra A. Obstructive sleep apnea, hypoxia, and nonalcoholic fatty liver disease. Am J Respir Crit Care Med 2019;199:830-841.

119. Jin S, Jiang S, Hu A. Association between obstructive sleep apnea and non-alcoholic fatty liver disease: a systematic review and meta-analysis. Sleep Breath 2018;22:841-851.

120. Umbro I, Fabiani V, Fabiani M, Angelico F, Del Ben M. Association between non-alcoholic fatty liver disease and obstructive sleep apnea. World J Gastroenterol 2020;26:2669-2681.

121. Aron-Wisnewsky J, Minville C, Tordjman J, Lévy P, Bouillot JL, Basdevant $A$, et al. Chronic intermittent hypoxia is a major trigger for non-alcoholic fatty liver disease in morbid obese. J Hepatol 2012;56:225-233.

122. Mishra P, Nugent C, Afendy A, Bai C, Bhatia P, Afendy M, et al. Apnoeic-hypopnoeic episodes during obstructive sleep apnoea are associated with histological nonalcoholic steatohepatitis. Liver Int 2008;28:1080-1086.

123. Trzepizur W, Boursier J, Mansour Y, Le Vaillant M, Chollet S, Pigeanne $T$, et al. Association between severity of obstructive sleep apnea and blood markers of liver injury. Clin Gastroenterol Hepatol 2016;14:1657-1661.

124. Kim D, Ahmed A, Kushida C. Continuous positive airway pressure therapy on nonalcoholic fatty liver disease in patients with obstructive sleep apnea. J Clin Sleep Med 2018;14:1315-1322.

125. Schwartz AR, Gold AR, Schubert N, Stryzak A, Wise RA, Permutt S, et al. Effect of weight loss on upper airway collapsibility in obstructive sleep apnea. Am Rev Respir Dis 1991;144(3 Pt 1):494-498.

126. Smith PL, Gold AR, Meyers DA, Haponik EF, Bleecker ER. Weight loss in mildly to moderately obese patients with obstructive sleep apnea. Ann Intern Med 1985;103:850-855.

127. Chung GE, Kim D, Kwak MS, Yim JY, Ahmed A, Kim JS. Longitudinal change in thyroid-stimulating hormone and risk of nonalcoholic fatty liver disease. Clin Gastroenterol Hepatol 2021;19:848-849.e1.

128. Kim D, Yoo ER, Li AA, Fernandes CT, Tighe SP, Cholankeril G, et al. Low-normal thyroid function is associated with advanced fibrosis among adults in the United States. Clin Gastroenterol Hepatol 2019;17:2379-2381

129. Chung GE, Kim D, Kim W, Yim JY, Park MJ, Kim YJ, et al. Nonalcoholic fatty liver disease across the spectrum of hypothyroidism. J Hepatol 2012;57:150-156.

130. Eshraghian A, Hamidian Jahromi A. Non-alcoholic fatty liver disease and thyroid dysfunction: a systematic review. World I Gastroenterol 2014;20:8102-8109.

131. He W, An X, Li L, Shao X, Li Q, Yao Q, et al. Relationship between hypothyroidism and non-alcoholic fatty liver disease: a systematic review and meta-analysis. Front Endocrinol (Lausanne) 2017;8:335.

132. Kim D, Kim W, Joo SK, Bae JM, Kim JH, Ahmed A. Subclinical hypothyroidism and low-normal thyroid function are associated with nonalcoholic steatohepatitis and fibrosis. Clin Gastroenterol Hepatol 2018;16:123-131.e1.

133. Kim D, Vazquez-Montesino LM, Escober JA, Fernandes CT, Cholankeril $\mathrm{G}$, Loomba $\mathrm{R}$, et al. Low thyroid function in nonalcoholic 
fatty liver disease is an independent predictor of all-cause and cardiovascular mortality. Am J Gastroenterol 2020;115:1496-1504.

134. Kelly MJ, Pietranico-Cole S, Larigan JD, Haynes NE, Reynolds CH, Scott N, et al. Discovery of 2-[3,5-dichloro-4-(5-isopropyl6-oxo-1,6-dihydropyridazin-3-yloxy)phenyl]-3,5-dioxo-2,3,4,5tetrahydro[1,2,4]triazine-6-carbonitrile (MGL-3196), a highly selective thyroid hormone receptor beta agonist in clinical trials for the treatment of dyslipidemia. J Med Chem 2014;57:3912-3923.

135. Kowalik MA, Columbano A, Perra A. Thyroid hormones, thyromimetics and their metabolites in the treatment of liver disease. Front Endocrinol (Lausanne) 2018;9:382.

136. Harrison SA, Bashir MR, Guy CD, Zhou R, Moylan CA, Frias JP, et al. Resmetirom (MGL-3196) for the treatment of non-alcoholic steatohepatitis: a multicentre, randomised, double-blind, placebocontrolled, phase 2 trial. Lancet 2019;394:2012-2024.

137. Goodman NF, Cobin RH, Futterweit W, Glueck JS, Legro RS, Carmina $E$, et al. American Association of Clinical Endocrinologists, American College of Endocrinology, and Androgen Excess and Pcos Society Disease State clinical review: guide to the best practices in the evaluation and treatment of polycystic ovary syndrome--part 1. Endocr Pract 2015;21:1291-1300.

138. Wu J, Yao XY, Shi RX, Liu SF, Wang XY. A potential link between polycystic ovary syndrome and non-alcoholic fatty liver disease: an update meta-analysis. Reprod Health 2018;15:77.

139. Kim JJ, Kim D, Yim JY, Kang JH, Han KH, Kim SM, et al. Polycystic ovary syndrome with hyperandrogenism as a risk factor for nonobese non-alcoholic fatty liver disease. Aliment Pharmacol Ther
2017;45:1403-1412.

140. Sarkar M, Terrault N, Chan W, Cedars MI, Huddleston HG, Duwaerts CC, et al. Polycystic ovary syndrome (PCOS) is associated with NASH severity and advanced fibrosis. Liver Int 2020;40:355359.

141. Paschou SA, Polyzos SA, Anagnostis P, Goulis DG, Kanaka-Gantenbein $C$, Lambrinoudaki I, et al. Nonalcoholic fatty liver disease in women with polycystic ovary syndrome. Endocrine 2020;67:1-8.

142. Vassilatou E. Nonalcoholic fatty liver disease and polycystic ovary syndrome. World J Gastroenterol 2014;20:8351-8363.

143. Miele L, Vallone S, Cefalo C, La Torre G, Di Stasi C, Vecchio FM, et al. Prevalence, characteristics and severity of non-alcoholic fatty liver disease in patients with chronic plaque psoriasis. J Hepatol 2009;51:778-786.

144. Gisondi P, Targher G, Zoppini G, Girolomoni G. Non-alcoholic fatty liver disease in patients with chronic plaque psoriasis. J Hepatol 2009;51:758-764.

145. Wenk KS, Arrington KC, Ehrlich A. Psoriasis and non-alcoholic fatty liver disease. J Eur Acad Dermatol Venereol 2011;25:383-391.

146. Phan K, Onggo J, Charlton O, Smith SD. Relationship between psoriasis and non-alcoholic fatty liver disease - updated systematic review and adjusted meta-analysis. Australas J Dermatol 2019;60:e352-e355

147. Campanati A, Ganzetti G, Di Sario A, Damiani A, Sandroni L, Rosa $L$, et al. The effect of etanercept on hepatic fibrosis risk in patients with non-alcoholic fatty liver disease, metabolic syndrome, and psoriasis. J Gastroenterol 2013;48:839-846. 